\title{
The use of extracorporeal carbon dioxide removal to avoid intubation in patients failing non-invasive ventilation - a cost analysis
}

Stephan Braune ${ }^{1 *}$, Hilmar Burchardi ${ }^{2}$, Markus Engel ${ }^{3}$, Axel Nierhaus ${ }^{1}$, Henning Ebelt ${ }^{4}$, Maria Metschke', Simone Rosseau ${ }^{5}$ and Stefan Kluge ${ }^{1}$

\begin{abstract}
Background: To evaluate the economic implications of the pre-emptive use of extracorporeal carbon dioxide removal $\left(\mathrm{ECCO}_{2} \mathrm{R}\right)$ to avoid invasive mechanical ventilation (IMV) in patients with hypercapnic ventilatory insufficiency failing non-invasive ventilation (NIV).
\end{abstract}

Methods: Retrospective ancillary cost analysis of data extracted from a recently published multicentre case-control-study $(n=42)$ on the use of arterio-venous $\mathrm{ECCO}_{2} \mathrm{R}$ to avoid IMV in patients with acute on chronic ventilatory failure. Cost calculations were based on average daily treatment costs for intensive care unit (ICU) and normal medical wards as well as on the specific costs of the $\mathrm{ECCO}_{2} \mathrm{R}$ system.

Results: In the group treated with $\mathrm{ECCO}_{2} \mathrm{R} \mathrm{IMV}$ was avoided in $90 \%$ of cases and mean hospital length of stay (LOS) was shorter than in the matched control group treated with IMV (23.0 vs. 42.0 days). The overall average hospital treatment costs did not differ between the two groups (41.134 vs. $39.366 €, p=0.8$ ). A subgroup analysis of patients with chronic obstructive pulmonary disease (COPD) revealed significantly lower median ICU length of stay (11.0 vs. 35.0 days), hospital length of stay (17.5 vs. 51.5 days) and treatment costs for the $\mathrm{ECCO}_{2} \mathrm{R}$ group (19.610 vs. $46.552 €, p=0.01$ ).

Conclusions: Additional costs for the use of arterio-venous $\mathrm{ECCO}_{2} \mathrm{R}$ to avoid IMV in patients with acute-on-chronic ventilatory insufficiency failing NIV may be offset by a cost reducing effect of a shorter length of ICU and hospital stay.

Keywords: Extracorporeal, Carbon dioxide removal, Mechanical ventilation, Cost analysis, Treatment costs

\section{Background}

Over the last decades invasive mechanical ventilation (IMV) is increasingly applied to critically ill patients of a more and more ageing and comorbid population [1]. At the same time the negative side effects of IMV, such as ventilator-associated lung injury (VILI), ventilatorassociated pneumonia (VAP), or ventilator-associated diaphragmatic dysfunction (VIDD) are recognised to contribute to morbidity and mortality [2-4]. In the last decade severe respiratory failure is increasingly treated with extracorporeal lung support, both for oxygenation

\footnotetext{
*Correspondence: sbraune@uke.de

1 Department of Intensive Care Medicine, University Medical Center Hamburg-Eppendorf, Martinistr. 52, 20246 Hamburg, Germany Full list of author information is available at the end of the article
}

(ECMO) and for carbon dioxide removal $\left(\mathrm{ECCO}_{2} \mathrm{R}\right)[5]$. Recently, a new strategy of applying $\mathrm{ECCO}_{2} \mathrm{R}$ to avoid IMV and its side-effects in patients with hypercapnic acute-on-chronic ventilatory failure not responding to non-invasive ventilation (NIV) has been described [6-10]. The most common condition of acute-on-chronic ventilatory failure frequently leading to ICU admissions is an acute exacerbation of a chronic obstructive pulmonary disease (COPD) [11]. Once IMV is commenced after failure of NIV, especially patients with chronic pulmonary disease carry an increased risk of prolonged weaning and length of ICU stay and their overall prognosis deteriorates [12-18].

Our research group has recently published a matched case-control study on the feasibility and safety of $\mathrm{ECCO}_{2} \mathrm{R}$

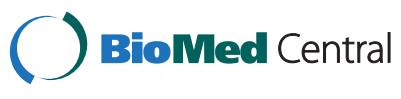

(C) 2015 Braune et al. Open Access This article is distributed under the terms of the Creative Commons Attribution 4.0 International License (http://creativecommons.org/licenses/by/4.0/), which permits unrestricted use, distribution, and reproduction in any medium, provided you give appropriate credit to the original author(s) and the source, provide a link to the Creative Commons license, and indicate if changes were made. The Creative Commons Public Domain Dedication waiver (http://creativecommons.org/publicdomain/zero/1.0/) applies to the data made available in this article, unless otherwise stated. 
in patients with NIV refractory acute on chronic hypercapnic ventilatory failure to avoid intubation [7]. The underlying chronic lung diseases of the study group are shown in Table 1. The extracorporeal device used was the socalled "interventional lung assist" (iLA", Novalung GmbH, Heilbronn, Germany), a pumpless, arterio-venous circuit for $\mathrm{ECCO}_{2} \mathrm{R}$ (av-ECCO${ }_{2} \mathrm{R}$ ), which has been licensed in 2006 [19] and since then been applied worldwide to approximately 10.000 patients [20]. Figure 1 shows the clinical setup of the system (Fig 1). Further details are described elsewhere [19].

Intubation was avoided in 19 of 21 patients (90\%) treated with av- $\mathrm{ECCO}_{2} \mathrm{R}$. Two patients in the av- $\mathrm{ECCO}_{2} \mathrm{R}$ group $(9.5 \%)$ had major bleeding complications. Ventilatorassociated complications, such as VILI, VAP and VIDD, could not be recorded for methodological reasons. The median duration of av- $\mathrm{ECCO}_{2} \mathrm{R}$ support and mechanical ventilation in the av- $\mathrm{ECCO}_{2} \mathrm{R}$ group was 9 days (range 1-116) and the median duration of mechanical ventilation in the control group was 21 days (range 1-47; $p=0.944$ ). Length of stay (LOS) in the ICU and in hospital was shorter in the av- $\mathrm{ECCO}_{2} \mathrm{R}$ group than that of the matched control group treated with invasive mechanical ventilation (15 vs. 30 days for LOS in ICU; $p=0.26$, and 23 vs. 42 days for LOS in hospital; $p=0.05$ ). Six month mortality was $33 \%$ in both groups.

Despite its increasing use, nothing is known about the economic impact of the use of this complex and costly technology to avoid intubation and IMV. Thus the purpose of this ancillary economic analysis was to evaluate if the reduction in hospital length of stay also translated to reduced treatment costs.

\section{Methods}

\section{Clinical study design and setting}

This ancillary retrospective economic evaluation was undertaken using data from a recently published multicentre case-control-study on the use of an arteriovenous extracorporeal carbon dioxide removal device $\left(\mathrm{av}-\mathrm{ECCO}_{2} \mathrm{R}\right)$ to avoid invasive mechanical ventilation in patients with acute on chronic respiratory insufficiency failing NIV [7]. The original study was conducted in four

Table 1 Diagnoses of chronic respiratory diseases

\begin{tabular}{lll}
\hline Diagnosis & $\begin{array}{l}\text { av-ECCO } \\
\text { R group }\end{array}$ & $\begin{array}{l}\text { MV group } \\
n(\%)\end{array}$ \\
\hline Severe COPD & $14(66.7)$ & $14(66.7)$ \\
Cystic fibrosis & $2(9.5)$ & $2(9.5)$ \\
Pulmonary Graft-vs-Host-Disease & $2(9.5)$ & $2(9.5)$ \\
Pulmonary fibrosis & $1(4.8)$ & $1(4.8)$ \\
Bronchial asthma & $1(4.8)$ & $1(4.8)$ \\
Pneumonia post lung transplant & $1(4.8)$ & $1(4.8)$ \\
\hline
\end{tabular}

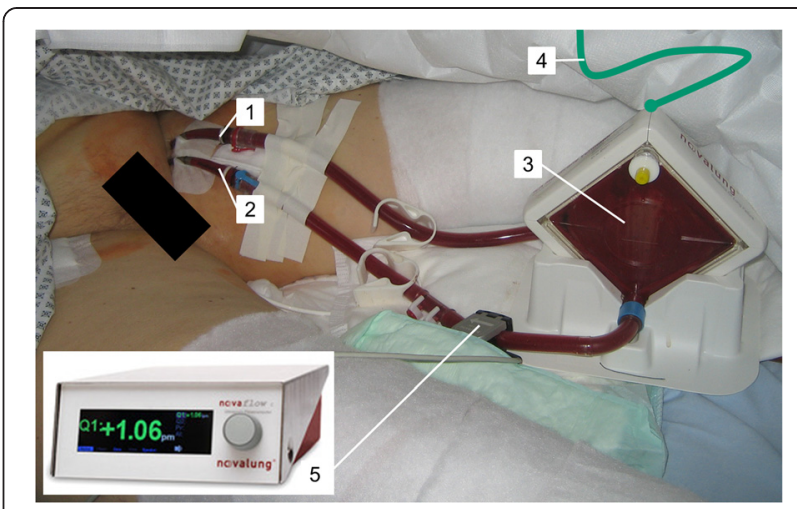

Fig. 1 Clinical setup and components of the pumpless, arterio-venous $\mathrm{ECCO}_{2} \mathrm{R}$ circuit "interventional lung assist" (iLA ${ }^{\oplus}$, Novalung GmbH, Heilbronn, Germany). The patient has given written consent for publication of this picture. 1 = arterial cannula, 2 = venous cannula, 3 = circuit including membrane for $\mathrm{ECCO}_{2} \mathrm{R}, 4=$ sweep gas $\left(\mathrm{O}_{2}\right)$, $5=$ ultrasonic flow-meter

tertiary level hospitals in Germany (Department of Intensive Care Medicine, University Medical Center Hamburg-Eppendorf; Department of Internal Medicine, Infectious Diseases and Respiratory Medicine, CharitéUniversitaetsmedizin Berlin; Department of Medicine III, University of Halle (Saale); Department of Cardiology and Intensive Care, Klinikum Bogenhausen, Munich). The data collected in the case-control-study were routine clinical data from medical records. Because of the retrospective study design patient consent to participate in the study was not applicable. The institutional ethics committees of all four participating centres approved anonymised data collection and analyses.

\section{Patients and interventions}

In 21 non-intubated patients with acute on chronic hypercapnic respiratory failure not responding to NIV and fulfilling criteria for intubation the iLA ${ }^{\circ}$ device for $\mathrm{ECCO}_{2} \mathrm{R}$ had been commenced in order to avoid imminent intubation. All of these patients had potentially reversible respiratory failure, e.g. acute exacerbation of COPD, and endotracheal intubation was deemed to carry a substantial risk of secondary complications due to prolonged invasive mechanical ventilation. All av-ECCO ${ }_{2} \mathrm{R}$ circuits were inserted at the bed-side in the ICU by the attending intensivists. The study centers matched control patients had also been admitted with hypercapnic acute-on-chronic ventilatory failure but in contrast were intubated and placed on invasive mechanical ventilation after NIV failure. The matching criteria for the control group selection were: 1) underlying diagnosis, 2) age, 3) simplified acute physiology score (SAPS-2), and 4) arterial $\mathrm{pH}$ before $\mathrm{ECCO}_{2} \mathrm{R}$ or intubation [7]. All control patients underwent daily awakening and spontaneous breathing trials for ventilatory weaning according to the local protocol. 
In addition to the economic evaluation of all 21 cases and their matched controls two subgroups were further analysed: The first subgroup was limited to those 17 $\mathrm{ECCO}_{2} \mathrm{R}$ cases and their corresponding controls, which subsequently were not lung transplanted. Because no control patient underwent lung transplantation costs were deemed not to be more comparable in this subgroup analysis. The second subgroup was further limited to all 12 cases with COPD not undergoing lung transplantation and their matched controls. The rationale for this was to evaluate a homogeneous patient group with the most common underlying diagnosis for acute on chronic ventilatory failure.

\section{Cost analysis}

The costs were analysed from the hospital's perspective and only direct treatment costs were evaluated [21]. All costs are expressed in 2013 Euro. Calculation of overall hospital costs for each case and control was based on average daily costs for treatment in the ICU and the medical normal ward. Average daily ICU costs were based on the results from the largest dataset on German national average daily ICU costs published by Moerer et al. [22]. Costs were derived from results of their subgroup analysis on patients on mechanical ventilation treated in tertiary level hospitals [22]. These costs included both variable and fixed costs. All costs derived in this study were 2003 Euros and were subsequently adjusted for the corresponding yearly inflation rates from 2004 until 2014, ranging from 0.3 to $2.6 \%$ according to the German Federal Statistics Office [23].

Average daily costs for treatment in the normal medical ward were derived from the 2013 cost calculations of the study centres administrative data. These costs also included both variable and fixed costs. Applied average daily costs for ICU treatment and treatment on the medical ward are shown in Table 2.

In addition, specific costs for av- $\mathrm{ECCO}_{2} \mathrm{R}$ treatment were calculated for each case based on the actual utilisation of consumables (cannulas and membranes) and length of treatment (daily rental costs for ultrasonic flow meter) (Fig. 1). Costs for consumables and daily rental costs for the flow meter were based on the manufacturer's official list prices for Germany in 2013. All cost items for av- $\mathrm{ECCO}_{2} \mathrm{R}$ and their prices are listed in Table 2. Any specific costs for mechanical ventilation were subsumed in the average daily ICU costs as derived in the original study by Moerer et al. [22].

ICU treatment costs for each case and control were calculated by multiplying the average daily ICU costs by the number of days spent in the ICU. In the case group specific costs for av-ECCO ${ }_{2} \mathrm{R}$ treatment were added to the ICU costs. Costs for treatment on the normal wards were calculated by multiplying average daily costs for a
Table 2 Values used for cost model

\begin{tabular}{|c|c|c|c|}
\hline \multirow[t]{2}{*}{ Item } & \multirow{2}{*}{$\begin{array}{l}\text { Value } \\
\text { (Euro) }\end{array}$} & \multicolumn{2}{|c|}{ Values for sensitivity analysis } \\
\hline & & $\begin{array}{l}\text { Minimum } \\
\text { value (Euro) }\end{array}$ & $\begin{array}{l}\text { Maximum } \\
\text { value (Euro) }\end{array}$ \\
\hline \multicolumn{4}{|l|}{ Hospital costs } \\
\hline - Daily costs for ICU & 1115 & 697 & 1534 \\
\hline $\begin{array}{l}\text { - Daily costs for normal } \\
\text { medical ward }\end{array}$ & 288 & 181 & 396 \\
\hline \multicolumn{4}{|l|}{$\mathrm{ECCO}_{2} \mathrm{R}$ related costs } \\
\hline - Single cannula & 458 & - & - \\
\hline $\begin{array}{l}\text { - Set with tubing and } \\
\text { Novalung-Membrane }\end{array}$ & 2335 & - & - \\
\hline $\begin{array}{l}\text { - Daily rental costs for } \\
\text { ultrasonic flow-meter }\end{array}$ & $62 /$ day & - & - \\
\hline
\end{tabular}

Abbreviations: $\mathrm{ICU}=$ intensive care unit, $\mathrm{ECCO}_{2} \mathrm{R}=$ Extracorporeal carbon dioxide removal

normal medical ward with the number of days actually spent on the normal ward after ICU discharge until hospital discharge or death. Finally, treatment costs for ICU and the normal ward were added to estimate the total hospital treatment costs.

To test the robustness of these cost estimates and to assess the impact of variations of daily ICU and normal ward costs, sensitivity analyses were performed. Average daily ICU costs calculated by Moerer et al. [22] were varied by applying the corresponding upper and lower standard deviations. Average daily costs for normal medical wards were varied by $30 \%$. Upper and lower margins for average daily treatment costs are presented in Table 2.

Diagnosis-related groups (DRG) and specific reimbursement plans for mechanical ventilation and extracorporeal lung support were not analysed.

\section{Statistical methods}

Results are presented as absolute numbers and percentages, as means with standard deviations for continuous variables if normally distributed, and as medians with ranges if not normally distributed. Comparisons between the two groups were performed using the $t$-test or the Mann-Whitney $U$ test depending on the data distribution. Two-sided $p<0.05$ values were considered significant. The software used was SPSS $^{\oplus}$ (version 20.0, SPSS Inc., Chicago, IL, USA).

\section{Results}

Median hospital length of stay (LOS) was shorter in the av- $\mathrm{ECCO}_{2} \mathrm{R}$ group than in the matched control group treated with IMV ( 23 vs. 42 days, $p=0.05$ ). The overall mean hospital treatment costs did not differ significantly between the two groups (41.134 vs. $39.366 €, p=0.80$ ). A sensitivity analysis did not reveal any significant differences when applying higher margins (53.689 vs. $54.155 €$, $p=0.98$ ) or lower margins ( 28.616 vs. $24.629 €, p=0.60$ ). Average ICU costs of the av-ECCO ${ }_{2} \mathrm{R}$ and the control 
group were $38.459 €(93.5 \%$ of all hospital costs) and $33.290 €(84.6 \%$ of all hospital costs), respectively. Average costs for av-ECCO ${ }_{2} \mathrm{R}$, included in the ICU costs of the case group, were $7.717 €(18.8 \%)$.

In the subgroup of 17 cases and controls without lung transplantation 6-months mortality rates were 41.2 and $35.3 \%$ respectively $(p=1.0)$. The median hospital LOS and ICU-LOS were 22 vs. 42 days $(p=0.41)$ and 13 vs. 30 days $(p=0.23)$. Overall mean hospital treatment costs did not differ significantly between av-ECCO ${ }_{2} \mathrm{R}$ cases and controls (33.843 vs. $39.731 € ; p=0.64)$ and a sensitivity analysis did not change these non-significant differences.

A subgroup analysis of each 12 non-lung-transplanted COPD cases and their matched COPD controls revealed no significant differences in 6-months mortality ( $33.3 \%$ vs. $25.0 \% ; p=1.0$ ). Hospital LOS (17.5 vs. 51.0 days; $p=0.01$ ) and ICU-LOS (11.0 vs. 35.0 days; $p=0.01$ ) were significantly shorter in the av-ECCO${ }_{2} \mathrm{R}$ group. Mean hospital treatment costs were also significantly lower in the $\mathrm{ECCO}_{2} \mathrm{R}$ group compared to the control group (19.610 vs. $46.552 €, p=0.01 ; 95 \%$ confidence interval $(95 \% \mathrm{CI})$ of absolute cost difference 5.769-48.113 €). A sensitivity analysis also showed significant differences. Detailed results of all groups and subgroups are presented in Table 3.

\section{Discussion}

This study is the first economic evaluation to compare the costs of an av- $\mathrm{ECCO}_{2} \mathrm{R}$ strategy to avoid IMV with costs for a conventional strategy of IMV after NIV failure in patients with acute-on-chronic ventilatory insufficiency. The overall hospital costs did not differ significantly between the av-ECCO ${ }_{2} \mathrm{R}$ group and the matched control group (53.689 vs. $54.155 €$ ) despite additional average costs of $7717 €$ per av- $\mathrm{ECCO}_{2} \mathrm{R}$ treatment. This did not change after excluding four $\mathrm{ECCO}_{2} \mathrm{R}$ patients who underwent lung transplantation and their controls. Thus, in this study the extra costs for av-ECCO $\mathrm{R}$ treatment were offset by lower hospital costs due to shorter average hospital length of stay in the av- $\mathrm{ECCO}_{2} \mathrm{R}$ group. A short length of stay in the ICU may per se result in a reduction of treatment costs, as it has previously been shown that length of ICU stay explains approximately 85 to $90 \%$ of interpatient variation in hospital costs [24].

Analysis of all COPD patients, the biggest and most homogenous diagnostic subgroup, revealed significantly lower overall hospital treatment costs in the av- $\mathrm{ECCO}_{2} \mathrm{R}$ group (19.610 vs. $46.552 €$ ) suggesting that $\mathrm{ECCO}_{2} \mathrm{R}$ to avoid intubation in patients with AECOPD and NIV failure may lead to a reduction of overall treatment costs. The potential economical relevance of this hypothesis is augmented by the fact that COPD has a high prevalence projected to be the fifth leading burden of disease worldwide by the year 2020 [11, 25].
Micro-costing was used for cost calculation of material consumption for av-ECCO ${ }_{2} \mathrm{R}$. Itemised cost evaluation of all other treatment costs was not feasible due to the retrospective study design. Instead, further cost analysis was performed by means of macro-costing. Average daily costs for ICU treatment used for cost analysis in this study were based on a previous study by Moerer et al. who calculated the average daily ICU costs in Germany by cost analyses of 51 German ICUs [22]. Their calculations included both variable and fixed costs as were costs for IMV. However, many health economic studies have demonstrated that fixed costs, especially staffing costs, account for up to $65 \%$ of all treatment costs [22, 26-29]. Thus variation of variable costs probably has a smaller effect of overall treatment costs. Moreover, sensitivity analysis did not change the results suggesting a degree of robustness of the results.

The rationale for applying the above mentioned data on average ICU costs also to $\mathrm{ECCO}_{2} \mathrm{R}$ patients despite the fact that the majority this group were not intubated and mechanically ventilated was, that from the experience of the participating study centres staff resource utilisation for management of invasive $\mathrm{MV}$ and av-ECCO${ }_{2} \mathrm{R}$ with or without non-invasive ventilation is comparable. In addition, costs for material consumption from MV were proposed to be relatively low and not significantly contributing to the overall treatment costs. Costs for treatment of side effects of av- $\mathrm{ECCO}_{2} \mathrm{R}$ observed in the original case-control study, such as bleeding and vascular surgery in one case, were not itemised separately. These costs were included in the average daily ICU costs as were treatment costs in the control group for side effects caused by invasive MV, such as treatment of ventilator-induced pneumonia. There is evidence that costs for patients on MV are significantly higher than costs for non-ventilated patients in ICU [22, 30,31 ] and that COPD patients on invasive mechanical ventilation have a longer stay in ICU and require higher treatment efforts than non-COPD patients on MV [32]. These data may further justify subsuming costs for side effects of av-ECCO ${ }_{2} \mathrm{R}$ into average daily ICU costs and may even suggest that a potential cost saving effect of avoiding MV with its complications and associated costs by applying av- $\mathrm{ECCO}_{2} \mathrm{R}$ may have been underestimated. On the other hand, additional costs for complications caused by av$\mathrm{ECCO}_{2} \mathrm{R}$ may also be associated with significant costs. The incidence of major, potentially costly complications was low in the av-ECCO ${ }_{2} \mathrm{R}$ group (9.5\%), but may have been underestimated because of low case numbers. Excluding 4 case-controls where the av- $\mathrm{ECCO}_{2} \mathrm{R}$ cases subsequently underwent lung transplantation with potentially higher costs did not change the results.

Since there are no valid national data on average daily costs for treatment of patients on normal wards in Germany who have previously been in ICU with 
Table 3 Comparisons of LOS and costs with sensitivity analysis and subgroup analysis

\begin{tabular}{|c|c|c|c|}
\hline \multicolumn{4}{|l|}{ All study patients } \\
\hline Variable & $\mathrm{ECCO}_{2} \mathrm{R}$ & Control & $p$ value \\
\hline Days [range] or Euro [SD] & $(n=21)$ & $(n=21)$ & \\
\hline Median length of stay in ICU & $15[4-137]$ & $30[4-66]$ & 0.58 \\
\hline Median length of stay in hospital & $23[4-137]$ & $42[4-248]$ & 0.05 \\
\hline Median duration of invasive MV & $0[0-47]$ & $21[4-47]$ & $<0.001$ \\
\hline Mean costs for $\mathrm{ECCO}_{2} \mathrm{R}$ & 7717 [7835] & - & - \\
\hline Mean total ICU costs & 38460 [43878] & $33291[22572]$ & 0.63 \\
\hline Mean total hospital costs & 41134 [43005] & 39366 [29903] & 0.88 \\
\hline Mean hospital costs with maximal values & $53689[56406]$ & 54155 [41133] & 0.98 \\
\hline Mean hospital costs with minimal values & $28616[18721]$ & $24629[18721]$ & 0.61 \\
\hline \multicolumn{4}{|c|}{ Subgroup analysis after exclusion of patients with lung transplantation } \\
\hline Variable & $\mathrm{ECCO}_{2} \mathrm{R}$ & Control & $p$ value \\
\hline Days [range] or Euro [SD] & $(n=17)$ & $(n=17)$ & \\
\hline Median length of stay in ICU & $13[4-137]$ & $30[4-66]$ & 0.41 \\
\hline Median length of stay in hospital & $22[4-137]$ & $42[4-248]$ & 0.23 \\
\hline Median duration of invasive MV & $0[0-47]$ & $21[1-47]$ & 0.001 \\
\hline Mean costs for $\mathrm{ECCO}_{2} \mathrm{R}$ & $5972[6522]$ & - & - \\
\hline Mean total ICU costs & 24989 [35273] & $33581[23656]$ & 0.41 \\
\hline Mean total hospital costs & $33843[40866]$ & $39731[31507]$ & 0.64 \\
\hline Mean hospital costs with maximal values & $44314[53924]$ & $54656[43340]$ & 0.54 \\
\hline Mean hospital costs with minimal values & $23405[27856]$ & $24857[19727]$ & 0.86 \\
\hline \multicolumn{4}{|l|}{ Subgroup analysis of patients with COPD } \\
\hline Variable & $\mathrm{ECCO}_{2} \mathrm{R}$ & Control & $p$ value \\
\hline Days [range] or Euro [SD] & $(n=12)$ & $(n=12)$ & \\
\hline Median length of stay in ICU & $11[4-23]$ & $35[4-66]$ & 0.004 \\
\hline Median length of stay in hospital & $17[4-43]$ & $51[4-248]$ & 0.04 \\
\hline Median duration of invasive MV & $0[0-22]$ & $27[4-47]$ & 0.001 \\
\hline Mean costs for $\mathrm{ECCO}_{2} \mathrm{R}$ & 4472 [1269] & - & - \\
\hline Mean total ICU costs & $13194[4611]$ & 39304 [25163] & 0.004 \\
\hline Mean total hospital costs & 19610 [7509] & $46552[34558]$ & 0.02 \\
\hline Mean hospital costs with maximal values & $25298[10115]$ & $64040[47536]$ & 0.01 \\
\hline Mean hospital costs with minimal values & 13942 [4938] & 29124 [21641] & 0.03 \\
\hline
\end{tabular}

Abbreviations: $L O S$ length of stay, $S D$ standard deviation, $C O P D$ chronic obstructive pulmonary disease, $I C U$ intensive care unit, $M V$ mechanical ventilation, $E C C O_{2} R$ Extracorporeal carbon dioxide removal

respiratory failure, estimating these costs was based on the study centres local average cost calculations. These locally derived calculations may be less generalizable. However, as only less than $25 \%$ of the total hospital costs were attributable to treatment on the normal ward, this potential error may be negligible.

This relationship is in line with findings of other studies that have shown that length of ICU stay was the main determinant of overall hospital cost variations [24, 33]. Again, sensitivity analysis had no significant effect on the results of this cost comparison.

Since cost calculations for $\mathrm{ECCO}_{2} \mathrm{R}$ were based on the pumpless arterio-venous $\mathrm{ECCO}_{2} \mathrm{R}$ device applied in the original study, these results cannot directly be applied to veno-venous, pump-driven devices for $\mathrm{ECCO}_{2} \mathrm{R}$ since their technology is more complex and extra cost apply for more expensive circuits and consoles. In addition, the clinical characteristics of patients and their controls of this study 
are quite specific as they had actually failed NIV and all patients in the control group had been intubated. Therefore they differ from the population of a recently published case-control-study in which patients at risk of NIV failure where treated with $\mathrm{ECCO}_{2} \mathrm{R}$ to avoid intubation [10]. In this study 25 patients treated with NIV and in addition a veno-venous, pump-driven $\mathrm{ECCO}_{2} \mathrm{R}$ device revealed a significantly lower intubation rate in comparison to their 21 controls treated with NIV alone (12 \% vs. $33 \%$ ). The LOS in ICU and hospital did not differ significantly between the two groups (8 vs. 12 and 24 vs. 22, respectively).

Further, this cost analysis did not take into account the health care provider's perspective on reimbursement plans, because aspects of diagnosis-related groups (DRG) or specific reimbursements for costly treatments and procedures such as invasive mechanical ventilation and extracorporeal lung support were not addressed. The rational for this was that reimbursement plans are individually negotiated between health care providers and healthcare payers on a local, regional and/or national level. Reimbursements do not necessarily represent factual costs and are highly variable between health care systems and over time [31, 34]. In fact, successfully avoiding intubation and MV by means of $\mathrm{ECCO}_{2} \mathrm{R}$ paradoxically may lead to an economic disadvantage for a specific health care provider if "lost" reimbursement rates for (prolonged) MV are not compensated for by reimbursement rates for $\mathrm{ECCO}_{2} \mathrm{R}$ treatment. Therefore further prospective and larger clinical and economic studies on strategies to avoid MV by means of $\mathrm{ECCO}_{2} \mathrm{R}$ are warranted to provide more evidence for rational decision making both in clinical practice and on a health care system level.

\section{Conclusion}

The additional costs of the use of $\mathrm{ECCO}_{2} \mathrm{R}$ to avoid IMV in NIV failure in a mixed group of patients with acute-onchronic ventilatory insufficiency may be offset by a potential cost reduction through a shorter length of hospital and ICU stay. Moreover, in patients with acute exacerbation of COPD this novel treatment strategy may not only hold clinical advantages, but may even reduce overall resource utilization and treatment costs. However, the preliminary and hypothesis-generating results of this pilot study must be validated in larger, prospective, multicentre, high quality randomised clinical trials not only evaluating clinical benefits but also paralleled by evaluation of costeffectiveness applying a micro-costing approach.

\section{Key message}

Additional costs associated with the use of arteriovenous extracorporeal carbon dioxide removal to avoid invasive mechanical ventilation in patients with acuteon-chronic ventilatory insufficiency failing non-invasive ventilation may be offset by a potential cost reduction through a shorter length of ICU and hospital stay.

\section{Abbreviations}

av-ECCO 2 : arterio-venous extracorporeal carbon dioxide removal; COPD: Chronic obstructive pulmonary disease; DRG: Diagnosis-related group; $\mathrm{ECCO}_{2} \mathrm{R}$ : Extracorporeal carbon dioxide removal; ECMO: Extracorporeal membrane oxygenation; ICU: Intensive care unit; IMV: Invasive mechanical ventilation; LOS: Length of stay; NIV: Non-invasive ventilation; VAP: Ventilatorassociated pneumonia; VILI: Ventilator-induced lung injury; VIDD: Ventilator induced diaphragmatic dysfunction.

\section{Competing interests}

AN, ME, SB and SR have received lecture honoraria from Novalung $\mathrm{GmbH}$, Heilbronn, Germany. SK has received lecture honoraria from Novalung GmbH and is a member of the advisory board. All other authors declare that they have no conflicts of interest.

\section{Authors' contributions}

$\mathrm{SB}, \mathrm{HB}, \mathrm{SR}$ and SK have made substantial contributions to the conception and design of the study. SB, ME, AN, HE, MM, SR and SK have substantially contributed to the acquisition of the data. SB, HB, SR and SK have made substantial contributions to analysis and interpretation of data. SB, HB and SK have drafted the submitted article. ME, AN, HE, MM and SR have revised it critically for important intellectual content. All authors read and approved the final manuscript.

\section{Acknowledgment}

Written patient consent was obtained for publication of the anonymised image in Fig. 1. The consent form is held by the authors' institution and is available for review by the Editorin-Chief.

\section{Author details}

'Department of Intensive Care Medicine, University Medical Center Hamburg-Eppendorf, Martinistr. 52, 20246 Hamburg, Germany. ${ }^{2}$ Bovenden, Germany. ${ }^{3}$ Department of Cardiology and Intensive Care, Klinikum Bogenhausen, Munich, Germany. ${ }^{4}$ Department of Medicine III, University of Halle (Saale), Halle, Germany. ${ }^{5}$ Department of Internal Medicine, Infectious Diseases and Respiratory Medicine, Charité-Universitaetsmedizin Berlin, Berlin, Germany.

Received: 5 July 2015 Accepted: 22 October 2015

Published online: 04 November 2015

\section{References}

1. Kahn JM, Le T, Angus DC, Cox CE, Hough CL, White DB, et al. The epidemiology of chronic critical illness in the United States. Crit Care Med. 2015;43:282-7.

2. Slutsky $A S$, Ranieri VM. Ventilator-induced lung injury. N Engl J Med. 2013;369:2126-36.

3. Jaber $S$, Jung B, Matecki S, Petrof BJ. Clinical review: ventilator-induced diaphragmatic dysfunction - human studies confirm animal model findings! Crit Care. 2011;15:206.

4. Timsit JF, Zahar JR, Chevret S. Attributable mortality of ventilator-associated pneumonia. Curr Opin Crit Care. 2011;17:464-71.

5. Agerstrand $\mathrm{CL}$, Bacchetta $\mathrm{MD}$, Brodie $\mathrm{D}$. ECMO for adult respiratory failure: current use and evolving applications. ASAIO J. 2014;60:255-62.

6. Terragni PP, Birocco A, Faggiano C, Ranieri VM. Extracorporeal $\mathrm{CO} 2$ removal. Contrib Nephrol. 2010;165:185-96

7. Kluge $S$, Braune $S A$, Engel M, Nierhaus A, Frings D, Ebelt $H$, et al. Avoiding invasive mechanical ventilation by extracorporeal carbon dioxide removal in patients failing noninvasive ventilation. Intensive Care Med. 2012;38:1632-9.

8. Burki NK, Mani RK, Herth FJ, Schmidt W, Teschler H, Bonin F, et al. A novel extracorporeal $\mathrm{CO}(2)$ removal system: results of a pilot study of hypercapnic respiratory failure in patients with COPD. Chest. 2013;143:678-86.

9. Crotti S, Lissoni A, Tubiolo D, Azzari S, Tarsia P, Caspani L, et al. Artificial lung as an alternative to mechanical ventilation in COPD exacerbation. Eur Respir J. 2012;39:212-5.

10. Del Sorbo SL, Pisani L, Filippini C, Fanelli V, Fasano L, Terragni P, et al. Extracorporeal Co2 removal in hypercapnic patients at risk of noninvasive 
ventilation failure: a matched cohort study with historical control. Crit Care Med. 2015:43:120-7.

11. Perera PN, Armstrong EP, Sherrill DL, Skrepnek GH. Acute exacerbations of COPD in the United States: inpatient burden and predictors of costs and mortality. COPD. 2012;9:131-41.

12. Nevins ML, Epstein SK. Predictors of outcome for patients with COPD requiring invasive mechanical ventilation. Chest. 2001;119:1840-9.

13. Esteban A, Anzueto A, Frutos F, Alia I, Brochard L, Stewart TE, et al. Characteristics and outcomes in adult patients receiving mechanical ventilation: a 28-day international study. JAMA. 2002;287:345-55.

14. Ucgun I, Metintas M, Moral H, Alatas F, Yildirim H, Erginel S. Predictors of hospital outcome and intubation in COPD patients admitted to the respiratory ICU for acute hypercapnic respiratory failure. Respir Med. 2006;100:66-74.

15. Texereau J, Jamal D, Choukroun G, Burgel PR, Diehl JL, Rabbat A, et al. Determinants of mortality for adults with cystic fibrosis admitted in Intensive Care Unit: a multicenter study. Respir Res. 2006;7:14.

16. Menzies R, Gibbons W, Goldberg P. Determinants of weaning and survival among patients with COPD who require mechanical ventilation for acute respiratory failure. Chest. 1989;95:398-405.

17. Combes A, Costa MA, Trouillet IL, Baudot J, Mokhtari M, Gibert C, et al. Morbidity, mortality, and quality-of-life outcomes of patients requiring $>$ or $=14$ days of mechanical ventilation. Crit Care Med. 2003;31:1373-81.

18. Pfeifer M. Chronic critically ill patients from a pneumological perspective. Med Klin Intensivmed Notfmed. 2013;108:279-84.

19. Bein T, Weber F, Philipp A, Prasser C, Pfeifer M, Schmid FX, et al. A new pumpless extracorporeal interventional lung assist in critical hypoxemia/ hypercapnia. Crit Care Med. 2006;34:1372-7.

20. Novalung GmbH. Annual Business Report. 2014. http://www.novalung.com. Accessed 27 June 2015.

21. Jegers $\mathrm{M}$, Edbrooke DL, Hibbert CL, Chalfin DB, Burchardi H. Definitions and methods of cost assessment: an intensivist's guide. ESICM section on health research and outcome working group on cost effectiveness. Intensive Care Med. 2002;28:680-5.

22. Moerer O, Plock E, Mgbor U, Schmid A, Schneider H, Wischnewsky MB, et al. A German national prevalence study on the cost of intensive care: an evaluation from 51 intensive care units. Crit Care. 2007;11:R69.

23. Consumer price index and inflation rates. German Federal Statistical Office. https://www.destatis.de/EN/Homepage.html. Accessed 27 June 2015

24. Rapoport J, Teres D, Zhao Y, Lemeshow S. Length of stay data as a guide to hospital economic performance for ICU patients. Med Care. 2003;41:386-97.

25. Mannino DM, Buist AS. Global burden of COPD: risk factors, prevalence, and future trends. Lancet. 2007:370:765-73.

26. Parviainen I, Herranen A, Holm A, Uusaro A, Ruokonen E. Results and costs of intensive care in a tertiary university hospital from 1996-2000. Acta Anaesthesiol Scand. 2004;48:55-60.

27. Edbrooke DL, Minelli C, Mills GH, lapichino G, Pezzi A, Corbella D, et al. Implications of ICU triage decisions on patient mortality: a cost-effectiveness analysis. Crit Care. 2011;15:R56.

28. Edbrooke D, Hibbert C, Ridley S, Long T, Dickie H. The development of a method for comparative costing of individual intensive care units. The Intensive Care Working Group on Costing. Anaesthesia. 1999;54:110-20

29. Flaatten $\mathrm{H}$, Kvale R. Cost of intensive care in a Norwegian University hospital 1997-1999. Crit Care. 2003;7:72-8.

30. Dasta JF, McLaughlin TP, Mody SH, Piech CT. Daily cost of an intensive care unit day: the contribution of mechanical ventilation. Crit Care Med. 2005;33:1266-71.

31. Heyland DK, Gafni A, Kernerman P, Keenan S, Chalfin D. How to use the results of an economic evaluation. Crit Care Med. 1999:27:1195-202.

32. Makris D, Desrousseaux B, Zakynthinos E, Durocher A, Nseir S. The impact of COPD on ICU mortality in patients with ventilator-associated pneumonia. Respir Med. 2011;105:1022-9.

33. Norris C, Jacobs P, Rapoport J, Hamilton S. ICU and non-ICU cost per day. Can J Anaesth. 1995;42:192-6.

34. Gyldmark M. A review of cost studies of intensive care units: problems with the cost concept. Crit Care Med. 1995:23:964-72.

\section{Submit your next manuscript to BioMed Central and take full advantage of:}

- Convenient online submission

- Thorough peer review

- No space constraints or color figure charges

- Immediate publication on acceptance

- Inclusion in PubMed, CAS, Scopus and Google Scholar

- Research which is freely available for redistribution

Submit your manuscript at www.biomedcentral.com/submit 